\title{
Making Social Media Work for You
}

\author{
Patricia P. Bloom ${ }^{1} \cdot$ Rajitha D. Venkatesh ${ }^{2} \cdot$ Evan S. Dellon $^{3} \cdot$ Joy W. Chang ${ }^{1}$
}

Accepted: 18 February 2021 / Published online: 28 April 2021

(c) The Author(s), under exclusive licence to Springer Science+Business Media, LLC, part of Springer Nature 2021

\begin{abstract}
Social media (SoMe) can be an effective professional tool for the gastroenterologist or trainee. SoMe can support a gastroenterologist's efforts to brand themselves, network, learn, educate, and advocate for patients. SoMe for professional use should be approached with specific aims in mind, in order to optimize impact and productivity.
\end{abstract}

\section{Introduction-The Why Is Important}

Many early career gastroenterologists feel like they are squeezing 20 hours of work into 10-hour days. Your time at work is valuable, so why should you spend some of it on social media (SoMe) for professional development? The value of SoMe is not necessarily in the number of followers you have on a given platform. Making the most out of SoMe for professional purposes requires reflection and selfexamination. You first need to identify your professional aspirations. Defining clear, desirable, and achievable career goals requires dedicated time for reflection, as well as conversations with peers and mentors. In the social sciences literature, setting and attaining goals aligned with one's passions has been linked to greater well-being, higher levels of meaningfulness, lower levels of depression, and even lower mortality [1]. Purposeful and goal-oriented planning are particularly important for trainees and junior faculty who are actively shaping the trajectory of their careers.

Professional goals, like people, are not one-size-fitsall. Even within the field of gastroenterology, there is extraordinary diversity among career paths. Some aspire to become master clinicians or proceduralists, some are driven

Patricia P. Bloom

ppbloom@med.umich.edu

1 Division of Gastroenterology and Hepatology, University of Michigan, 1500 E Medical Center Dr, Ann Arbor, MI 48109, USA

2 Division of Pediatric Gastroenterology, Hepatology and Nutrition, Nationwide Children's Hospital, Columbus, $\mathrm{OH}$, USA

3 Division of Gastroenterology, Center for Esophageal and Swallowing Disorders, University of North Carolina, Chapel Hill, NC, USA primarily by financial incentives, some are motivated to provide education on a specific disease, and some aspire to become independent and productive academic researchers. The personal motivations of each gastroenterologist should drive their career path and, consequently, their goals. Varying by career path, professional goals can include personal branding, staying up to date with professional communities and the latest medical literature, expanding and maintaining one's professional network, continuing one's education, and advocating for worthy causes (Fig. 1).

Armed with professional goals, the next step is to identify specific gaps between where you are today and your aspirations. Once you have identified a roadmap of smaller and larger next-steps needed for your professional growth, SoMe can be a powerful tool to help you reach those goals. Though SoMe is not a tool for every single professional "todo list" item, it can be a tool for many. In a hypothetical example, your goals are to gain expertise in celiac disease, build a reputation as an expert, and address patient-centered needs in this condition. Through conversations with peers and mentors, and a process of reflection and active investigation, you develop a plan of action: using SoMe you connect and collaborate with dietitians, promote your reputation as a celiac disease expert, engage with celiac disease patient support groups to better understand their unmet needs, and seek out sponsorship relationships with thought leaders and industry.

If you enter SoMe aimlessly, you may have some fun, but you also may end up disappointed. Marketing surveys indicate that people are spending more and more time using SoMe, currently averaging 144 min daily [2]. Without direction, you may find that you spend countless minutes (or more) and become frustrated by things that ultimately do not positively impact your goals. Since SoMe is 
Fig. 1 Process for using SoMe to accomplish professional goals

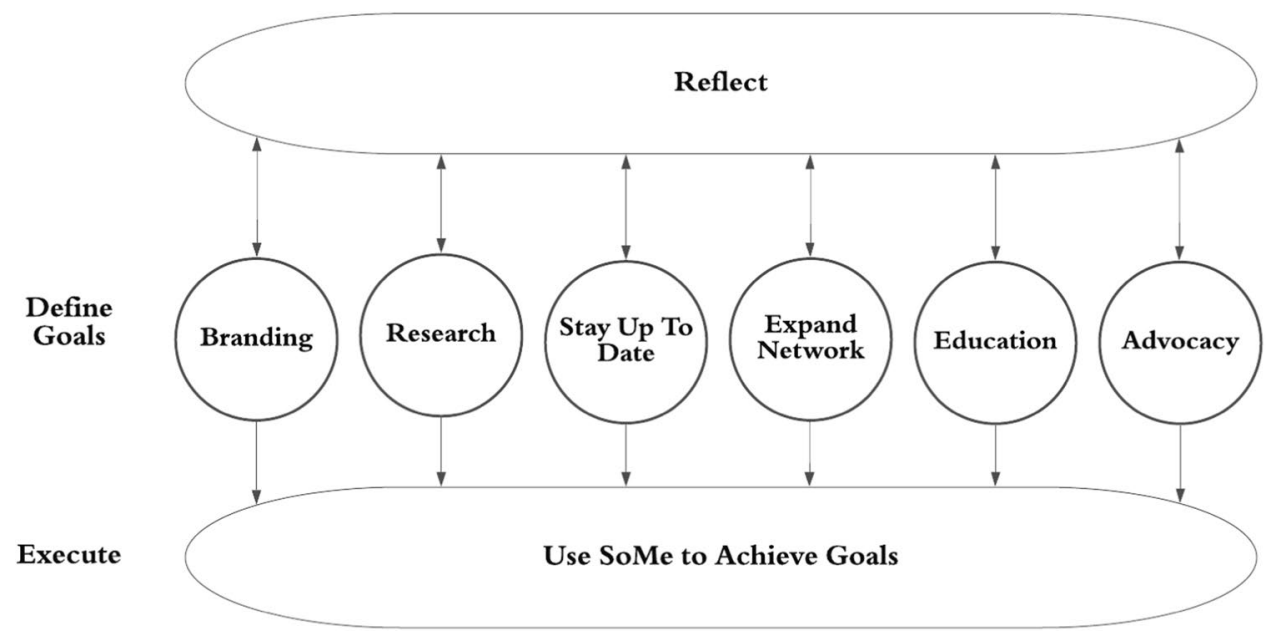

an unpaid task to add to your list, and as such you should use it only so much as it is beneficial. By identifying your professional purpose on SoMe platforms from the start, you are more likely to gain what you want from them and leave the time-wasting and frustration behind. Setting specific time limits on SoMe activities may also reduce the risk of wasted time and effort. Here we illustrate ways and practical tips that SoMe can be used to serve common professional goals (Table 1).

\section{Shape Your Brand}

Presenting a clear personal brand can be highly advantageous in medicine. Every gastroenterologist has a brand, but not every gastroenterologist proactively shapes their brand. While professional goals are internally determined, brand is what other people perceive about you-it is by definition externally determined [7] Jeff Bezos, the founder of Amazon, once said "your brand is what people say about you when you're not in the room"'[8]. Personal brand is similar to the "one-liner" used to succinctly describe a patient's medical presentation, but even more brief. Mary is the expert

Table 1 Practical tips for using some to achieve professional goals

\begin{tabular}{|c|c|}
\hline \multirow[t]{4}{*}{ Branding } & Develop your brief biography to post on your SoMe accounts. Solicit peer feedback \\
\hline & Tweet about your own research, work, and accomplishments \\
\hline & $\begin{array}{l}\text { Maintain professionalism: follow Health Insurance Portability and Accountability Act (HIPAA), ensure } \\
\text { validity of post content, follow institution guidelines }\end{array}$ \\
\hline & Learn SoMe strategies from inside and outside academic medicine [3-5] \\
\hline \multirow[t]{4}{*}{ Research } & Promote your research or research group \\
\hline & Use SoMe data as a means to produce research [6]. \\
\hline & Form collaborative research relationships \\
\hline & Publicize and increase awareness of research results \\
\hline \multirow[t]{3}{*}{ Stay Up-to-Date } & Follow GI and hepatology society accounts (e.g., ACG, AASLD, AGA, NASPGHAN) \\
\hline & $\begin{array}{l}\text { Follow key journal accounts (e.g., @AGA_Gastro, @AmJGastro, @AGA_CGH,@HEP_Journal, @ } \\
\text { DDS_Journal, @JPGNonline) }\end{array}$ \\
\hline & Follow coverage of important meetings like Digestive Disease Week and the Liver Meeting \\
\hline \multirow[t]{3}{*}{ Expand Network } & Aim to connect with 1 new SoMe contact/a unit of time (frequency determined by you) \\
\hline & Promote the work of your peers with regular engagement, comments, and retweets \\
\hline & Connect in-person with SoMe contacts at conferences \\
\hline \multirow[t]{2}{*}{ Education } & Follow@ScopingSundays, @MondayNightIBD, @GiJournal, @LiverFellow, and other similar accounts \\
\hline & Set a goal to post educational content \# times/week (frequency determined by you) \\
\hline \multirow[t]{3}{*}{ Advocacy } & Search and follow key patient advocates and patient groups \\
\hline & Reach out to patient groups if you have a specific proposal \\
\hline & Engage in SoMe campaigns \\
\hline
\end{tabular}


endoscopist. Eduardo is the fatty liver researcher. For a gastroenterologist, brand is determined by colleagues, patients, promotion committees, industry groups, and many others who interact with that person in a professional capacity. Brand is influenced by the work you do, as well as how you convey that work to the world.

A well-defined personal brand that accurately reflects your professional goals can propel a gastroenterologist's career forward. Branding makes you more memorable. Humans, especially very busy humans, rely heavily on schemas and memory short-cuts in order to process and interpret the world. When a program director asks a colleague about whom to admit to their program, when a division chair is thinking about whom to reach out regarding potential employment, or when a faculty member is considering whom to invite to give grand rounds, they will be relying on schemas. All of these important individuals are human, and they are relying on the shortcuts in their mental circuitry to remember who you are. Having a clear and desirable brand can make you more likely to be invited to talks, given grants, or get jobs. If you effectively shape the way others think of you, opportunities will follow.

SoMe can be an enormous asset in proactively shaping your professional brand. The first step in creating a brand on SoMe starts before you create an account. First you need to know your brand, or more importantly, what you want to be your brand. What do you want your one-liner to be when another gastroenterologist thinks of you? If your brand is general gastroenterology educator, you should have a different SoMe presence than someone who is a basic scientist with an interest in hepatocellular carcinoma. The second step is setting up your SoMe accounts to support that brand. Who you follow, what you write about, your biography (or "about me" section), and which platforms you use should all support your desired brand. You can use SoMe to share publications, research and other endeavors that gently selfpromote and steer your audience toward your desired brand. Finally, integrity and humility, or a lack thereof, is a major component of one's brand. Ensure that your SoMe content is accurate. If you are uncertain about a particular post or tact on SoMe, consider pausing before posting on it or asking a colleague for a second opinion. In the current pandemic era of virtual training and job interviews, clear branding online is essential. You should ensure that a program director or division chair's Google or Twitter search reveals material that supports your brand and mission [9].

SoMe activity is also increasingly being incorporated into the curriculum vitae and academic promotion process [10]. Standards have been developed in order to evaluate the impact and quality of SoMe scholarship, which must be original, advance the field, be archived and disseminated, and available for transparent feedback by the medical community. The SoMe content must be objectively evaluated on the basis of impact metrics (e.g., number of page views), peer review of the work, size of the digital platform, as well as an examination of how the SoMe work impacts overall career development [11].

A well-crafted SoMe presence not only opens doors for professional development (e.g., lectures, employment, collaborations), but can also improve patient relations. As the medical community of providers, trainees, professional organizations, and researchers grows into this virtual space, our patients actively seek out knowledge, expert opinions, and peer support on several SoMe platforms. Patients and referring providers will come see you if they like what you say on SoMe, whereas they may avoid you if they are put off by your comments. In a survey of over 3000 SoMe users on multiple platforms, the vast majority $(85 \%)$ enjoyed learning medical information from SoMe and $75 \%$ followed at least one doctor [12]. Furthermore, $75 \%$ reported that they would schedule an appointment with a doctor they followed on SoMe, even if it required travel. Survey respondents felt that SoMe was a way to get to know their doctor better and reassured them that their doctor was up to date with technology. Especially if your professional goals include developing a panel of patients with a certain gastrointestinal disease, SoMe is a way for those patients to not only find you, but perhaps help you to build a patient base and build a reputation as a leader.

\section{Lurking Is OK!}

Lurking on SoMe is not as ominous as it sounds. Lurking has been defined in the social science literature as those who post infrequently or never, and have a passive presence on SoMe. In fact, lurkers have been the majority in many online communities and in some cases appear to benefit more than active posters in terms of overall well-being and perceived social support $[13,14]$.

Returning to our main premise, knowing your WHY on $\mathrm{SoMe}$ is essential. If your main reason for being on SoMe is to have your finger on the pulse of your community, then it may be advantageous to lurk and stay up-to-date on the latest research or evidence-based practices. Especially in the era of the COVID-19 pandemic when in person conferences are not possible, SoMe enables gastroenterologists to learn about high-yield scientific abstracts and presentations. Furthermore, reading posts from gastroenterology thought leaders and journals can keep you in the know, without consuming the time and energy it takes to create a post yourself.

A low maintenance account with a few followers can be useful, even without active and regular posting. Being a passive presence enables colleagues to find you and opens doors for opportunities to connect with one another. Those using SoMe frequently are disappointed when they cannot find 
their colleagues on a platform, especially when promoting their work.

\section{Life Is Who You Know}

Networking is central to successful medical practice. Since academic promotions are in part based on reputation and professional impact, SoMe can help other physician-scientists in your field get to know you. If handled with finesse, this can lead to invitations to speak, collaborate, and write. In clinical practice, SoMe can help you build a brand amongst patients and generate referrals for your specific area of interest. Branching out beyond gastroenterology to your professional interests such as education, quality improvement, and advocacy can extend your professional network and lead to future dividends down the road.

SoMe also provides an enormous opportunity to build community with other young gastroenterologists, who are in a similar stage of their career. By directly messaging peers or conversing publicly via posts, SoMe serves as a basis for peer mentorship and cross-institution (even international) friendships. Numerous research collaborations have blossomed from interactions on \#GITwitter and \#LiverTwitter, including a recent multi-center study of COVID-19 outcomes in patients with liver disease which developed from Twitter contacts and communications [15]. In an international collaboration, the term Scopemanship began as a Twitter hashtag and blossomed into a modern day code of ethics for endoscopists and trainees alike, encompassing domains of leadership, training, decision making and situational awareness, teamwork, communication, and compassion [16]. For many trainees and early career gastroenterologists, connecting via SoMe has cultivated a sense of camaraderie and extended the meaning of "fellowship" among extramural peers, one that is further solidified by live interactions during conferences and meetings.

\section{Education}

Being a medical educator may be a part of your professional goals - to patients, providers, or both. Tweetorials are a string of tweets increasingly employed in \#GITwitter to provide provider peer education [17]. Posting board review questions is another way of creating interactive and educational SoMe content. Similar to creating a lesson or presentation, formulating educational SoMe content takes time, but can lend credence to one's reputation as a medical educator [18]. SoMe also provides a means for self-education. Twitter forums such as @ ScopingSundays, @MondayNightIBD, @GiJournal, and @LiverFellow are easy ways to encounter high-yield topics often generated by fellow junior gastroenterologists. Active participation in such forums can provide a microphone for your teaching, as well as a way to learn. As mentioned above, a large general population survey of SoMe users found that the majority enjoy learning medical information from SoMe [12]. Despite these positives, there are potential pitfalls to avoid. Be sure to avoid providing medical advice over SoMe, violating HIPAA, or getting ensnared in a public argument with a patient or other providers [17].

\section{Advocacy}

Your call to patient care may include advocacy for a specific patient population or issue. SoMe can be used as a powerful platform to promote and raise awareness for your cause. There are numerous examples of SoMe advocacy by gastroenterologists, from supporting a ban on high-powered magnet sets easily swallowed by children, to advocating for nutrition equity (@NutritionEquity on Twitter), to raising awareness about the benefits of colon cancer screening [19].

While medical providers should avoid offering medical advice to patients online, SoMe can facilitate safe interactions with patient voices through patient advocacy groups. Forming close relationships with patient advocacy groups via SoMe can have a variety of benefits for the provider: improved understanding of patient concerns, generate referrals for a desired condition within your scope of practice, or even in more tangible ways such as collaborating on research projects or recruiting for clinical trials and studies. For example, one of our authors forged relationships with national patient advocacy groups on Facebook and Twitter, who have helped to recruit subjects for via SoMe for survey research [20].

\section{Choosing the Platform}

SoMe encompasses many platforms, each with a different audience and potential utility. Choose your platform(s) wisely. For gastroenterologists in academia, Twitter is a popular medium for intra-provider and researcher communication. Beyond gastroenterology, physicians certainly have a presence on other platforms [21]. Facebook and Instagram are more frequently used by patient organizations and patients themselves [12]. For many physicians hoping to disseminate evidenced-based medicine to a specific patient population or to promote their practice, a well-curated Facebook and Instagram account may go farther than a Twitter account. Instagram is similarly a potential platform for patient discourse, but may be less formal. Furthermore, formulating the image or infographic to use on Instagram may take a greater time investment. TikTok, another SoMe 
platform with a large user base, has an uncertain status in the USA at the time of this commentary.

\section{Conclusions}

SoMe is an essential modern tool for branding, research, education, networking, and patient advocacy. It allows for a gastroenterologist to effectively build their professional network, promote their academic pursuits, collaborate across boundaries that would otherwise have been challenging to surmount, and advocate for reform and patient causes. The benefits of SoMe have only become more pronounced with our reliance on virtual interaction during the COVID-19 pandemic. As career paths and goals may evolve over time, tailoring SoMe usage to your advantage may also change to reach those targets. Nevertheless, if SoMe is used without specific intention or defined purpose, it can lead to time wasting and reduced quality time spent away from work.

\section{Key Messages}

- For the young gastroenterologist, using social media for professional development should be purposeful and in line with the pursuit of one's career goals.

- If wielded thoughtfully, social media is essential and effective tools for branding, networking, education, and patient advocacy.

Funding Patricia Bloom receives funding from the American College of Gastroenterology (ACG Junior Faculty Award) and the American Association for the Study of Liver Diseases (AASLD Advanced Hepatology Award).

\section{Disclosure}

Conflicts of interest Patricia Bloom serves as a consultant for Synlogic.

\section{References}

1. Schippers MC, Ziegler N. Life crafting as a way to find purpose and meaning in life. Front Psychol. 2019;10:2778.

2. Henderson G. How much time does the average person spend on social media? Vol 2020: digitalmarketing.org; 2020.

3. Ellering N. How often to post on social media? CoSchedule Blog. Vol 20202017:https://coschedule.com/blog/ how-often-to-post-on-social-media/.
4. Cheplygina V, Hermans F, Albers C, Bielczyk N, Smeets I. Ten simple rules for getting started on Twitter as a scientist. PLoS Comput Biol. 162020:e1007513.

5. Gray D, Fisher D. Making social media work for your practice. GI \& Hepatology News; 2018.

6. Chang JW, Dellon ES. Challenges and Opportunities in Social Media Research in Gastroenterology. Dig Dis. 2021 (submitted for publication).

7. Borman-Shoap E, Li ST, St Clair NE, Rosenbluth G, Pitt S, Pitt MB. Knowing Your Personal Brand: What Academics Can Learn From Marketing 101. Acad Med. 2019;94:1293-1298.

8. Arruda W. The Most Damaging Myth about Branding. Vol 2020. www.forbes.com2016.

9. Hansen K. Personal Branding for Life Sciences Professionals. 2020. www.biospace.com2019.

10. Shapiro M, Wray C, Arora V. Social Media, Podcasts, and Blogs on a Professional Curriculum Vitae. 2019.

11. Cabrera D, Vartabedian BS, Spinner RJ, Jordan BL, Aase LA, Timimi FK. More than likes and tweets: creating social media portfolios for academic promotion and tenure. J Grad Med Educ. 2017;9:421-425.

12. Crawford NME-H, Emily. Utilization of social media for personal branding by physicians. American Society for Reproductive Medicine; 2019; Pennyslvania.

13. Edelmann N. Reviewing the definitions of "lurkers" and some implications for online research. Cyberpsychol Behav Soc Netw. 2013;16:645-649.

14. Han JY, Hou J, Kim E, Gustafson DH. Lurking as an active participation process: a longitudinal investigation of engagement with an online cancer support group. Health Commun. 2014;29:911-923.

15 Kim D, Adeniji N, Latt N, et al. Predictors of outcomes of COVID-19 in patients with chronic liver disease: US multi-center study. Clin Gastroenterol Hepatol. 2020. https://doi.org/10.1016/j. cgh.2020.09.027.

16. Bollipo S, Bilal M, Siau K, Charabaty A. How to introduce scopemanship into your training program. Gastroenterology. 2020;159:1648-1652.

17. Bilal M, Oxentenko AS. The impact of twitter: why should you get involved, and tips and tricks to get started. Am J Gastroenterol. 2020;115:1549-1552.

18. Sotto-Santiago S, Sharp S, Mac J. The power of social media in the promotion and tenure of clinician educators. MedEdPORTAL. 2020;16:10943.

19. Rudolph B. Children can easily swallow high-powered magnets, it's time to ban them for good. 2020; https://www.usatoday.com/ story/opinion/2020/03/11/children-can-easily-swallow-toy-magne ts-its-time-ban-column/4974445002/, 2020.

20. Chang JW, Rubenstein JH, Mellinger JL, et al. Motivations, barriers, and outcomes of patient-reported shared decision making in Eosinophilic Esophagitis. Dig Dis Sci. 2020.

21. Crawford NM, Evans-Hoeker E. Understanding the role of social media for physicians. American Society for Reproductive Medicine; 2019; Pennyslvania.

Publisher's Note Springer Nature remains neutral with regard to jurisdictional claims in published maps and institutional affiliations. 